\title{
Terapia ocupacional na atençáo extra-hospitalar oferecida pelo hospital
}

\author{
Marilia Bense Othero \\ Terapeuta Ocupacional, Mestre em Ciências, Departamento de Medicina Preventiva, Faculdade de Medicina, \\ Universidade de São Paulo - USP, Membro do Conselho Executivo, Coordenadora, Equipe de Saúde Mental e \\ da Equipe de Monitoramento, Grupo MAIS/SP, Coordenadora, Comitê de Terapia Ocupacional, \\ Associação Brasileira de Linfoma e Leucemia - ABRALE, Professora, Instituto Paliar, São Paulo, SP, Brasil
}

\begin{abstract}
Resumo: A "Atenção Extra-Hospitalar oferecida pelo Hospital” refere-se às intervenções oferecidas pelo hospital no domicílio dos usuários e é uma das áreas de desempenho da especialidade "Terapia Ocupacional em Contextos Hospitalares". O objetivo deste artigo é apresentar os principais conceitos relacionados ao campo e descrever a prática da Terapia Ocupacional na área. Atenção domiciliar, atendimento domiciliar, internação domiciliar e visita domiciliar são os termos preconizados pelo Ministério da Saúde e que compõem tal área de desempenho. $\mathrm{O}$ foco da intervenção do terapeuta ocupacional dependerá do nível assistencial, e poderá incluir: preparo e orientações para a alta e pós-alta, avaliação e adequação do ambiente domiciliar, resgate de atividades significativas, promoção da autonomia e da independência, reabilitação cognitiva, estimulação sensorial, orientações quanto ao posicionamento, confecção e prescrição de dispositivos de auxílio, além de orientações a familiares e cuidadores. São muitos desafios a serem enfrentados pelo profissional da área, como a complexidade do contexto domiciliar, a remuneração e a organização da assistência, o trabalho em equipe, a construção de redes de suporte, entre outros; porém, a assistência extra-hospitalar é um espaço no qual a atuação do terapeuta ocupacional é de fundamental importância.
\end{abstract}

Palavras-chave: Terapia Ocupacional, Cuidados Paliativos, Hospitalização, Políticas Públicas.

\section{Occupational therapy in extra-hospital care offered by hospitals}

\begin{abstract}
The Extra-hospital Care offered by hospitals is one of the performance areas of the "Occupational Therapy in Hospital Care Contexts" specialty and refers to the assistance provided by the hospitals at the patients' homes. The aim of this article is to introduce the area main concepts and describe the practice of Occupational Therapy. There are four kinds of home health care assistance in Brazil, as recommended by the Ministry of Health, and all of them are in the area of occupational performance. The main focus of the occupational therapist's intervention depends on the assistance level, and it may include preparation and information for hospital discharge, assessment and adaptation of the home environment, recovery of meaningful activities, promotion of independence and autonomy, cognitive rehabilitation, sensorial stimuli, information about positioning, prescription and manufacturing of adaptive devices, and guidance for family and care givers. There are many challenges to be faced in this professional area, such as: domiciliary context complexity, payment and organization, team work, support networks, etc. Occupational Therapy plays a very important role in extra-hospital care.
\end{abstract}

Keywords: Occupational Therapy, Hospice Care, Hospitalization, Public Policies.

Autor para correspondência: Marilia Bense Othero, Grupo MAIS, Av. Jurubatuba, 481, Vila Cordeiro, CEP 04583-100, São Paulo, SP, Brasil, e-mail: m.othero@grupomaissaude.com.br

Recebido em 26/2/2012; Aceito em 1/3/2012. 


\section{Introdução}

Este artigo surgiu da palestra de mesmo nome, proferida no Simpósio "Terapia Ocupacional em Contextos Hospitalares”, realizado no XII Congresso Brasileiro de Terapia Ocupacional e IX Congresso Latino Americano de Terapia Ocupacional, na data de 13 de outubro de 2011, em São Paulo-SP. O conteúdo do artigo baseia-se - além de referências bibliográficas da área - no trabalho desenvolvido pelo setor de Terapia Ocupacional do Grupo MAIS (Hospital Premier, São Paulo Internaçóes Domiciliares e ProAtiva Saúde), em São Paulo-SP.

O termo "Atenção extra-hospitalar oferecida pelo Hospital” refere-se às intervençóes oferecidas pelo hospital no domicílio dos usuários, incluindo-se a (re) construção de redes de suporte.

O texto que aqui segue está organizado da seguinte forma: apresentaçáo de conceitos importantes relacionados à assistência domiciliar, o âmbito da Terapia Ocupacional na especialidade de Terapia Ocupacional em Contextos Hospitalares, a intervenção técnica do terapeuta ocupacional, e considerações finais acerca do tema.

\section{Conceitos importantes}

De maneira global, segundo Carletti e Rejani (2005), a assistência domiciliar define-se como um serviço de saúde em que as açóes são desenvolvidas no domicílio do paciente, por uma equipe multiprofissional, a partir de seu diagnóstico clínico e do contexto sociocultural em que está inserido. Cavalcanti et al. (2007) explicam que a finalidade da intervenção na assistência domiciliar pode ser em cinco âmbitos:

- Preventivo: para vigilância de quadros clínicos situacionais ou de agravamento de quadros crônicos;

- Curativo: com objetivo de resolver o quadro atual do doente, buscando-se seu completo restabelecimento;

- Paliativo: não havendo possibilidade de cura ou reabilitaçáo, abrange medidas que visam proporcionar conforto (físico, psíquico, social e espiritual);

- Reabilitador: para restauração de padróes motores, cognitivos, emocionais e funcionais; e

- Educativo: tem como foco a mudança de rotinas e hábitos, através de mecanismos de orientação e aprendizagem.
Complementando as informaçóes, Amaral et al. (2001) resumem os objetivos da assistência domiciliar em saúde:

- Humanização do atendimento;

- Maior rapidez na recuperaçáo do paciente;

- Diminuição no risco de infecção hospitalar;

- Otimização de leitos hospitalares para pacientes que deles necessitem;

- Redução do custo por dia de internação;

- Proximidade do paciente com sua família e contexto sociocultural;

- Prevenção e minimização de eventuais sequelas; e

- Reduçáo de internaçáo por recidivas.

Diante dos aspectos mencionados, o plano de tratamento pode incluir, entre outros aspectos, a execução do cuidado, com procedimentos de diversas complexidades, medidas de conforto, higiene e segurança; a orientação e a integração da família e do paciente no planejamento das ações e no cuidar; além da supervisão das tarefas assumidas pelo cuidador.

Porém, é importante ressaltar que as condiçôes socioeconômicas no Brasil podem dificultar a organizaçáo do cuidado no ambiente domiciliar: frequentemente são observadas situaçóes de isolamento do doente, com reduçóes progressivas na sua participação no ambiente familiar e comunitário. Assim, é preciso oferecer cuidados ampliados - não somente envolvendo aspectos clínicos ou biológicos - mas em suas dimensóes sociais, emocionais, ocupacionais e espirituais. $\mathrm{O}$ trabalho em equipe, portanto, é primordial neste âmbito assistencial.

A principal população atendida nesta modalidade são os idosos; frente ao envelhecimento populacional no Brasil (fenômeno também mundial), não associado a melhoria da qualidade de vida e nem à adequação do sistema de saúde, a atenção domiciliar surge como uma alternativa que beneficia esta camada da população (juntamente com os incapacitados crônicos), que tem muitas dificuldades de acesso ao sistema (inadequação urbana e arquitetônica mais desorganizaçáo), e tendem a permanecer isoladas em seus domicílios, sem receber atendimento (CARLETTI; REJANI, 2005).

Historicamente, Amaral et al. (2001) e Cavalcanti et al. (2007) mencionam que a primeira referência de cuidados domiciliares sistematizados é o Dispensário de Boston, nos Estados Unidos, em 1796, atualmente New England Medical Center, no qual atendimentos médicos eram prestados nas casas de pessoas carentes. No Brasil, Cavalcanti et al. (2007) 
explicam que a assistência domiciliar iniciou-se em 1919, com a criação do Serviço de Enfermeiras Visitadoras no Rio de Janeiro, para assistência materno-infantil e de tisiologia, e posteriormente para o combate a epidemias.

Amaral et al. (2001) trazem outro marco da história brasileira: a criação do sistema de assistência domiciliar à saúde no Hospital do Servidor Público Estadual de São Paulo, em 1967, tendo como objetivo a redução de leitos ocupados e, para isso, foi implantado um atendimento específico a cuidados de baixa complexidade clínica. Prado, Formighieri e Santana (2009) mencionam mais alguns destaques da história da assistência domiciliar no Estado de São Paulo: Serviço de Assistência Domiciliar da Clínica Gerontológica do Hospital do Servidor Público Municipal de São Paulo, de 1994; Núcleo de Assistência Domiciliar Interdisciplinar (NADI) do Hospital das Clínicas da Faculdade de Medicina da Universidade de São Paulo, de 1996; Serviço de Assistência Domiciliária ao Idoso (SADI) do Centro de Referência à Saúde do Idoso do Município de Guarulhos, de 1997; e o Serviço de Visita Domiciliar do Hospital das Clínicas da Faculdade de Medicina de Ribeirão Preto, de 1999.

Sobre a inclusão do terapeuta ocupacional, Cavalcanti et al. (2007) explicam que nos EUA ela ocorreu em março de 1963, através do Serviço de Extensão Hospitalar (SEH), com jornada de 4 horas por dia. Em dezembro do mesmo ano, o serviço de Terapia Ocupacional no SEH passou a ser integral, com um terapeuta ocupacional contratado em cada equipe. No Brasil, as autoras também abordam esta inclusão: na portaria no. 2416 do SUS, de 23 de março de 1998, é citada a participação do terapeuta ocupacional na formação das equipes multidisciplinares de assistência em domicílio. $\mathrm{O}$ Conselho Federal de Medicina, na resolução no. 1668, de 2000, também dispóe da participação do terapeuta ocupacional na formação de equipes de assistência domiciliar, com atribuiçóes a serem estabelecidas pelo conselho profissional.

Os termos que conceituam a assistência em domicílio são diversos. No Brasil, a resoluçáo RDC no. 11, de 26 de janeiro de 2006, da Anvisa em conjunto com o Ministério da Saúde, apresenta as terminologias oficiais sobre assistência domiciliar no país: atenção domiciliar, atendimento domiciliar, internação domiciliar, visita domiciliar (LACERDA et al., 2006). Seguem as definiçóes abaixo, conforme apresentado em artigo de Lacerda et al. (2006), por meio de revisão de literatura:
- Atenção Domiciliar: termo genérico, que envolve açôes de promoção à saúde, prevenção e tratamento de doenças, e reabilitação, desenvolvidas em domicílio;

- Atendimento Domiciliar: é um conjunto de atividades de caráter ambulatorial, programadas e continuadas, desenvolvidas em domicílio, voltadas a pessoa com problemas agudos, que e, função deles está temporariamente impossibilitada de comparecer à unidade de saúde. São considerados sinônimos: assistência domiciliar e cuidado domiciliar;

- Internação Domiciliar: é uma atividade continuada, com oferta de tecnologia e de recursos humanos, equipamentos, materiais e medicamentos, para pacientes em estados mais complexos, que demandem assistência semelhante à oferecida em ambiente hospitalar. A portaria MS/GM No. 2.529, de 20 de outubro de 2006, institui especificamente a internação domiciliar no âmbito do SUS, tendo como populaçóes - alvo: idosos, portadores de doenças crônico degenerativas agudizadas, portadores de patologias que necessitem de cuidados paliativos e portadores de incapacidade funcional, provisória ou permanente; e

- Visita Domiciliar: contato pontual de profissionais de saúde com as populaçôes de risco, pacientes e seus familiares, para coleta de informaçóes e/ou oferta de orientaçốes. São, portanto, desenvolvidas ações de orientação, educação, levantamento de possíveis soluçôes de saúde.

A atençáo domiciliar tem especificidades, e o contexto sociocultural do paciente deve ser considerado para a efetividade das intervençóes propostas. As vantagens relacionadas ao tratamento e a observaçáo in loco, por vezes apresentadas por autores como Cavalcanti et al. (2007), podem também funcionar como fatores que complexificam a assistência prestada. Assim, conforme já mencionado, deve-se reforçar as propostas terapêuticas de caráter ampliado, envolvendo não somente os aspectos médico - biológicos.

\section{Terapia ocupacional na assistência extra-hospitalar oferecida pelo hospital}

A "Terapia Ocupacional em Contextos Hospitalares" foi considerada área de especialidade da Terapia Ocupacional na Resolução COFFITO 
no 371, de 06 de novembro de 2009, publicada no DOU no 228, Seção 1, em 30 de novembro de 2009, página 852. Segundo texto publicado na Carta de São Paulo, de 2010, produzida pelo Grupo de Trabalho da Terapia Ocupacional em Contextos Hospitalares (reconhecido pela Associação Brasileira de Terapia Ocupacional/ABRATO), tem-se a seguinte definição para esta especialidade:

Especialidade do terapeuta ocupacional que atua em instituiçôes hospitalares de saúde de pequeno, médio ou grande porte, seja hospital geral ou especializado, inclusive os hospitais psiquiátricos e penitenciários. Visa contribuir com a proteção, promoção, prevenção, recuperação da saúde e reabilitação do indivíduo e da coletividade, pautado na concepçáo de integralidade e humanização da assistência à saúde. Além da assistência terapêutico-ocupacional propriamente dita, a atuação no contexto hospitalar abrange a gestão, o ensino e pesquisa visando à formação e o aperfeiçoamento das competências e habilidades profissionais no campo de conhecimento e prática profissional em contextos hospitalares. (GRUPO..., 2010, p. 03).

Como áreas de atuação, tem-se:

- Desempenho ocupacional em Atençáo intra-hospitalar;

- Desempenho ocupacional em Atenção extra-hospitalar oferecida por Hospital; e

- Desempenho ocupacional em Cuidados Paliativos.

A atenção extra-hospitalar oferecida por hospital inclui: visita domiciliar, assistência domiciliar, internação domiciliar e rede de suporte.

\section{Intervenção terapêutica ocupacional: da teoria à prática}

Ainda durante o período de internação hospitalar, o terapeuta ocupacional poderá desenvolver açóes relacionadas ao ambiente domiciliar do paciente. Para um adequado preparo para a alta, algumas avaliaçôes são necessárias, como por exemplo:

- Necessidades de suporte para o cuidado em domicílio, como adequação dos cuidadores, equipamentos sociais e serviços disponíveis no território, dispositivos de tecnologia assistiva, etc; e
- Ambiente domiciliar: condiçóes ambientais, presença de barreiras arquitetônicas, riscos para quedas, etc.

Isto é, já no início do projeto de alta para um paciente, o terapeuta ocupacional deverá ter seu olhar voltado às necessidades que serão apresentadas no domicílio. Além disso, a construção de redes com os profissionais que darão seguimento ao cuidado, a elaboração de relatórios e solicitaçôes constituirão outras maneiras de assistência extra-hospitalar, neste momento.

A orientação no momento da alta do paciente é fundamental. Em reunióes com a família, conversas pontuais ou através de relatórios ou folhetos, cabe ao terapeuta ocupacional informar sobre as necessidades do paciente, as adaptações necessárias, reforço de orientaçôes prévias. E, já havendo uma avaliação do ambiente domiciliar, conforme mencionado anteriormente, esta tarefa será facilitada.

Após a alta, considerando-se o paciente e a família, suas necessidades e suas redes de suporte, o terapeuta ocupacional irá estabelecer seu plano terapêutico - sempre em conjunto com a equipe multiprofissional - em diferentes modalidades: assistência pontual, acompanhamento e visitas regulares, ou internação domiciliar.

Assistência pontual. O monitoramento do paciente após a alta poderá ser uma estratégia utilizada; este monitoramento pode ser feito através de contatos telefônicos periódicos, nos quais o terapeuta ocupacional irá avaliar suas condições de saúde, como está sua adaptação no ambiente domiciliar, quais as ajudas necessárias e outros encaminhamentos possíveis.

Além disso, também podem ser realizadas visitas de luto, para familiares de pacientes que faleceram no ambiente hospitalar, e eram acompanhados pelo terapeuta ocupacional. Acolhimento, escuta do familiar, avaliação e (re)orientação quanto ao cotidiano e à retomada de papéis anteriormente exercidos podem ser algumas das açôes neste modelo de intervenção.

Quando necessário, outras visitas pontuais podem também ser realizadas para reavaliação do ambiente e das condiçóes do domicílio, reorientaçôes relacionas à independência e à autonomia do paciente, necessidades de ajudas técnicas, etc.

Acompanhamento e visitas regulares. Nesta modalidade, será elaborado um programa de assistência terapêutica ocupacional, em conjunto com o restante da equipe. O foco da intervenção é - de maneira geral - a independência e na autonomia para atividades de vida diária, seja através do 
resgate e/ou descoberta de atividades significativas, reabilitação cognitiva, adequação do ambiente e do funcionamento domiciliar, orientação aos familiares e cuidadores.

O plano de acompanhamento inicia-se com uma avaliação, incluindo aspectos como: capacidade funcional, desempenho ocupacional, história de vida, repertório de atividades, avaliação ambiental, entrevista com o cuidador, entre outros. Com foco nos Cuidados Paliativos, Silva e Kovacs (2007) mencionam também que na assistência domiciliar o terapeuta ocupacional deve avaliar as capacidades do paciente para a independência na vida e fornecer sugestôes práticas para favorecer sua participaçáo no ambiente familiar.

O plano terapêutico dependerá do perfil do doente atendido, das necessidades específicas de cada momento do processo de adoecimento, da rede de suporte disponível, e dos recursos institucionais disponibilizados para a equipe. Rocha et al. (2010) descrevem possibilidades de seguimentos semanais, quinzenais e até mesmo mensais para os pacientes.

A promoção de independência e da autonomia pode ser trabalhada através de diferentes recursos, conforme já mencionado. $\mathrm{O}$ uso de atividades (sejam elas expressivas, artísticas, artesanais, etc) pode promover o resgate de capacidades e de sentidos no cotidiano dos pacientes, além de - de acordo com Silva e Kovacs (2007) - poder ajudar o paciente a falar e refletir sobre o que está vivendo, como se sente e o que deseja explorar naquele momento. Mello et al. (2004) reiteram a importância do fazer atividades pois, por meio de seu fazer, o sujeito pode se reconhecer enquanto tal reelaborar suas questóes e experiências, bem como seu processo de adoecimento e hospitalização, além de reconstruir sua história.

Já o treino de atividades de vida diária ou a prescrição e/ou a confecção de adaptaçóes para realiza-las podem ser outras estratégias. No domicílio, acompanhar o momento do almoço ou do banho pode ser uma fonte útil para o terapeuta ocupacional; acompanhar as atividades e realizar as orientaçóes (seja para o paciente ou para o cuidador) facilita para que se consiga a máxima independência possível. Paim et al. (2009) aponta um fato importante: muitas vezes, após a alta hospitalar, a família passa a superproteger o paciente; com a participação do mesmo nas atividades, sua reabilitação pode se acelerar, além de ser um estímulo para sua autoestima.

A estimulação cognitiva é fundamental para pacientes com sequelas neurológicas e idosos com processos demenciais. Memória, pensamento abstrato, raciocínio, prejuízo do julgamento, cálculo, orientação espaço-temporal são alguns dos aspectos citados por Paim et al. (2009). Exercícios de memória, jogos, atividades com palavras, recursos para orientação (como relógios e calendários, por exemplo) são apenas algumas possibilidades a serem trabalhadas.

As adaptaçôes ambientais podem ser diversas, com os mais diferentes objetivos: aumento da largura das portas para favorecer a circulaçáo com cadeira de rodas; instalaçáo de rampas, barras de apoio no banheiro, grades removíveis na cama para prevenção de quedas; indicaçáo de cadeira de banho; retirada de tapetes; instalação de pisos antiderrapantes; adequação da iluminação do ambiente; utilização da cama hospitalar; modificaçôes na localização de móveis e equipamentos, entre tantos outros (PRADO; FORMIGUIERI; SANTANA, 2009; SILVA; KOVACS, 2007).

Entretanto, Silva e Kovacs (2007) reforçam a importância do vínculo com a família e com o paciente para a orientação quanto às adaptaçóes ambientais, devendo-se conhecer as necessidades dos mesmos. É preciso paciência e perseverança nas orientações, até que a família e o paciente façam as transformaçóes necessárias; o lar de uma pessoa é recheado de histórias, marcas e afetos, e mudanças aparentemente simples podem ter um grande impacto na vida dos sujeitos que ali residem.

A partir da prática como terapeutas ocupacionais na assistência domiciliar, Rocha et al. (2010) apresentam os seguintes resultados: enriquecimento do cotidiano, maximização da independência por meio de recursos de tecnologia assistiva, aumento da circulaçấo social, resgate de atividades significativas, melhoria de funçóes cognitivas, melhora do estado emocional geral. As autoras explicitam o quanto as intervençóes possibilitam melhoria da qualidade de vida, com ampliação da independência para atividades de vida diária e diminuição das situaçóes de apatia; além disso, afirmam que com a melhora emocional e a presença de estímulos e atividades em seu cotidiano, ocorrem influências positivas em seu estado clínico, com aumento da capacidade funcional e de seu desempenho ocupacional, evitando-se internaçôes recorrentes.

Em um estudo randomizado sobre a efetividade da intervençáo, Graff et al. (2006) concluem que a Terapia Ocupacional melhora a funcionalidade diária do paciente com demência, além de reduzir a sobrecarga do cuidador. Já para pacientes com sequela de acidente vascular encefálico, estudos de Steultjens et al. (2003) e Landi et al. (2006) concluem que os pacientes atendidos pelos terapeutas ocupacionais apresentam maiores níveis de independência em atividades de vida diária. 
Internação Domiciliar. Nesta modalidade assistencial, também se estabelecerá um plano contínuo de Terapia Ocupacional, entretanto os casos são mais complexos, especialmente do ponto de vista clínico. Não é incomum atendimento a pacientes com sequelas muito graves, em estado vegetativo ou em dependência de oxigênio e aparelhos que auxiliem na respiração, por exemplo. $\mathrm{O}$ posicionamento e a prevenção de deformidades, a estimulação sensorial, a confecção e a prescrição de tecnologia assistiva, assim como a já mencionada orientação aos familiares e cuidadores serão focos principais da assistência.

O posicionamento adequado - seja no leito, na cadeira, na cadeira de rodas - é fator primordial para o conforto do paciente e para a prevenção de deformidades e de úlceras por pressão. Há coxins, rolos e almofadas disponíveis para compra, mas o terapeuta ocupacional também poderá confecciona-los a partir de materiais simples (espuma e tecido) ou mesmo encontrar objetos do domicilio a serem utilizados (como almofadas e travesseiros). Novamente, a orientação sobre sua utilização deve ser constante, avaliando-se sempre a maneira e a adequaçáo do posicionamento feito pelos familiares e cuidadores. As órteses devem ser indicadas de acordo com o prognóstico de cada doente; em Cuidados Paliativos, recomenda-se o uso de materiais alternativos para criar dispositivos mais confortáveis (OTHERO; ARINI; FURTADO, 2010a, b).

Já a estimulação sensorial - através de toques, texturas, aromas, músicas, sabores, fotografias, etc - pode se constituir como uma estratégia importante para a assistência a pacientes com sequelas neurológicas mais graves, proporcionando resgate de sua identidade e de sua história de vida (OTHERO; ARINI; FURTADO, 2010a, b; OTHERO; ROCHA; ARINI, 2009). A indicação de relaxamento e massagens podem também auxiliar no controle de diversos sintomas, como dor, dispneia, constipaçáo, ansiedade e agitação.

A prescrição e/ou confecção de dispositivos de tecnologia assistiva poderá proporcionar para pacientes com limitaçóes mais severas o resgate da independência e da autonomia do cotidiano. Adaptaçóes para o uso do computador, para transferências cama-cadeira, para a realização de atividades de lazer somente com uma das máos, para leitura na cama, para comunicação alternativa são apenas alguns exemplos possíveis. Porém, Prado, Formighieri e Santana (2009) orientam que o terapeuta ocupacional considere a condiçáo socioeconômica de cada núcleo familiar, procurando indicar opçóes de baixo custo, e priorizando aquelas que podem ser feitas pela própria equipe.
Assistência ao familiar e cuidador. O suporte e a orientação ao familiar e ao cuidador são tarefas fundamentais na atenção extra-hospitalar, desde o momento da avaliação. Segundo documento produzido pelo Comitê de Terapia Ocupacional da Associação Brasileira de Linfoma e Leucemia (2008), os objetivos gerais da intervenção do terapeuta ocupacional junto ao familiar/cuidador são:

- Orientar para que tenham mais informaçóes, melhor segurança com o tratamento e/ou que possam praticar determinadas açóes junto ao paciente;

- Facilitar a comunicação entre paciente e cuidador, potencializando esta relaçáo; e

- Oferecer espaços de troca, reflexão e escuta.

As orientaçôes incluirão, por exemplo: procedimentos a serem realizados junto ao paciente, como treino de AVDs, facilitação da independência, posicionamento no leito; estímulo à realização de atividades prazerosas pelo paciente; abordagens de conforto; construção de meios alternativos para comunicação.

Para pacientes com déficit cognitivo (parcela importante da população atendida em domicílio), Paim et al. (2009) apresentam algumas orientaçôes fundamentais, que valem ser destacadas:

- Manter atitudes positivas junto ao paciente;

- Tratá-lo de acordo com sua idade;

- Incentivá-lo na participação em atividades domésticas, familiares e sociais;

- Ajudá-lo a rememorar sua biografia (nome e sobrenome, idade, nascimento, endereço, familiares, marcos da história);

- Estimular o resgate de informaçóes por meio de fotos, gravuras, jornais, etc;

- Utilizar calendário e relógio, além de outras estratégias facilitadoras, lendo sempre junto com o paciente;

- Não dar respostas prontas quando houver dificuldade para lembrar-se de algum assunto, preferindo dicas ou indícios e não o apressando; $\mathrm{e}$

- Estabelecer uma rotina diária.

O envolvimento da família no processo de estimulação é de fundamental importância para que as orientações recebidas sejam reforçadas em casa de forma sistematizada, visando melhor desempenho pessoal, profissional e social do indivíduo, resultando em uma melhor qualidade de vida. (PAIM et al., 2009, p. 60). 
Prado, Formighieri e Santana (2009) ressaltam que as orientaçôes devem ser dadas gradativamente, considerando-se também o vínculo e o tempo de assistência para cada paciente e família. Em uma mesma visita, as autoras sugerem que cada membro da equipe não ultrapasse três orientaçôes, para facilitar a adesão ao tratamento; depois, no decorrer dos retornos, acrescentam-se outras orientaçóes e informaçōes.

Além disso, é preciso também acolher o familiar em seu sofrimento, oferecendo-o espaço de escuta e apoio; são muitas mudanças, novas situaçóes e informaçóes, havendo a necessidade de reorganização e adaptação de toda a família - com isso, é imprescindível que a assistência ao familiar seja integral, em suas dimensões física, psíquica, ocupacional, relacional, social e espiritual.

E, não é somente no espaço do domicilio que este cuidado pode ser prestado. Grupos de suporte e de orientação, no espaço do hospital ou em algum espaço na comunidade, são uma estratégia de grande valia. Em um artigo publicado por Othero et al. (2011), os autores relatam uma experiência de encontros temáticos mensais, aos sábados, sendo realizado previamente o levantamento dos temas de interesse dos familiares e cuidadores.

Foram aplicados 51 questionários (18 familiares e 33 cuidadores contratados), correspondendo a 42 pacientes (62\% dos pacientes atendidos pelo programa de assistência extra-hospitalar daquela equipe). Em um perfil demográfico destes familiares/cuidadores, observou-se que entre os cuidadores predominam as faixas etárias até 59 anos, e o nível de escolaridade até ensino médio completo; já entre os familiares, a faixa etária predominante é acima de 59 anos, com escolaridade de nível superior completo (OTHERO et al., 2011).

Sobre os temas de interesse, destacaram-se os temas que envolvem a saúde e o cuidado ao próprio cuidador; o tema mais assinalado $(74,51 \%)$ foi sobre como lidar com os transtornos de comportamento do paciente, ressaltado pelos autores como uma fonte de angústia e dificuldade para o cuidador/familiar (OTHERO et al., 2011).

Em uma pesquisa bibliográfica realizada por Rosa, Rossigali e Soares (2010), evidencia-se a necessidade e a preocupação em haver um espaço na clínica da Terapia Ocupacional para acolher familiares e cuidadores,

[...] uma vez que essas pessoas estão diretamente envolvidas com o sofrimento, a dor e várias situações desconhecidas e assustadoras que interferem na convivência familiar. (ROSA; ROSSIGALI; SOARES, 2010, p. 15).
Pediatria. Conforme já mencionado, na assistência domiciliar a principal população atendida são os idosos; porém, algumas consideraçôes sobre a assistência em Pediatria devem ser feitas. Usualmente, as crianças que acabam sendo atendidas nesta modalidade são aquelas com síndromes mais raras, especialmente nos casos em que há demanda de suporte ventilatório (oxigênio, ventilação mecânica, etc).

O foco do terapeuta ocupacional, além de aspectos gerais já mencionados (posicionamento, adaptaçōes, ambiente, etc), deverá estar no brincar, pois esta é a principal atividade significativa para a criança, além de promover seu desenvolvimento global. Já a família é o principal meio de acesso às informaçóes sobre a criança, além de receberem todas as orientaçóes sobre o cuidado e o tratamento, devendo também ser acolhida pelo terapeuta ocupacional.

\section{Considerações finais}

A "Assistência extra-hospitalar oferecida pelo Hospital" constitui um campo importante de atuaçáo no terapeuta ocupacional nos Contextos Hospitalares. Em todo o plano de intervenção, o terapeuta ocupacional deverá manter um plano de cuidados integrado com o restante da equipe, avaliando e reavaliando sempre os resultados de suas intervençôes. Rocha et al. (2010) indicam, inclusive, alguns critérios de alta: melhora do paciente com a intervenção; desinteresse do paciente e/ou família acerca do tratamento terapêutico ocupacional; alta do programa de assistência extra-hospitalar.

Além disso, o suporte ao profissional que atua na área é fundamental. Reuniōes clínicas, discussóes de caso, suporte técnico, discussão de textos, apoio à pesquisa e à participação em cursos e eventos, e - principalmente - supervisão em Terapia Ocupacional são algumas das maneiras de oferecer tal suporte. $\mathrm{O}$ apoio e o acolhimento à equipe também devem constituir foco de ação da instituição que oferece a assistência.

São muitos desafios a serem enfrentados neste contexto. A complexidade do ambiente domiciliar; os espaços permeados por histórias, marcas e afetos; a remuneração e a organização da assistência (ainda precárias em muitos serviços); o trabalho em equipe; a formação específica do terapeuta ocupacional para tal atuaçáo; a construçáo de redes de suporte de fato - são apenas alguns a serem mencionados.

Mas, é imprescindível reforçar e ressaltar que a assistência extra-hospitalar é espaço de atuação do terapeuta ocupacional, e - cada vez mais - a categoria terá que se organizar para ocupar tal lugar. 


\section{Referências}

AMARAL, N. N. et al. Assistência Domiciliar à Saúde (Home Health Care): sua História e sua Relevância para o Sistema de Saúde Atual. Revista Neurociências, São Paulo, v. 9, n. 3, p. 111-117, 2001.

ASSOCIAÇÃO BRASILEIRA DE LINFOMA E LEUCEMIA - ABRALE. Terapia Ocupacional na Oncologia. In: OTHERO, M. B. (Org.). Comitê de Terapia Ocupacional da Associação Brasileira de Linfoma e Leucemia. 2008. Mimeo.

CARLETTI, S. M. M.; REJANI, M. I. Atenção Domiciliária ao Paciente Idoso. In: PAPALEO NETTO, M. (Org.). Gerontologia: A velhice e o envelhecimento em visão globalizada. São Paulo: Atheneu, 2005. p. 415-430. CAVALCANTI, A.; GALVÃO, C.; QUEIROZ, M. E. G. Home care. In: CAVALCANTI, A.; GALVÃO, C. Terapia Ocupacional: Fundamentação e prática. Rio de Janeiro: Guanabara Koogan, 2007. p. 508-511.

GRAFF, M. J. L. et al. Community based occupational therapy for patients with dementia and their care givers: randomized controlled trial. BMJ: British Medical Journal, London, v. 333, n. 7580, p. 1196, Dec. 2006. PMid:17114212 PMCid:1693594. http://dx.doi. org/10.1136/bmj.39001.688843.BE

GRUPO NACIONAL DE TERAPIA OCUPACIONAL EM CONTEXTOS HOSPITALARES - GNTO. Carta de São Paulo. São Paulo: GNTO, 2010. Mimeo.

LACERDA, M. R. et al. Atenção à Saúde no Domicílio: modalidades que fundamentam sua prática. Saúde $e$ Sociedade, São Paulo, v. 15, n. 2, p. 88-95, maio/ago. 2006.

LANDI, F. et al. Effects of an Occupational Therapy Program on functional outcomes in older stroke patients. Gerontology, Basel, v. 52, n. 2, p. 85-91, 2006. PMid:16508315. http://dx.doi.org/10.1159/000090953

MELLO, M. A. F. et al. Processo avaliativo em Terapia Ocupacional. In: DE CARLO, M. M. R. P.; LUZO, M. C. M. (Orgs.). Terapia Ocupacional: Reabilitação Física e Contextos Hospitalares. São Paulo: Rocca, 2004. p. 74-98.

OTHERO, M. B.; ARINI, T. S.; FURTADO, M. T. S. Terapia Ocupacional e cuidados paliativos na assistência ao paciente com sequela neurológica grave. In: CONGRESSO INTERNACIONAL DE CUIDADOS PALIATIVOS, 4., 2010, São Paulo. Anais... São Paulo: ANCP, 2010a. Apresentação Oral.

OTHERO, M. B.; ARINI, T. S.; FURTADO, M. T. S. O uso de materiais alternativos para confecção de órteses em Cuidados Paliativos. In: CONGRESSO INTERNACIONAL DE CUIDADOS PALIATIVOS, 4., 2010, São Paulo. Anais... São Paulo: ANCP, 2010b. Pôster.

OTHERO, M. B.; ROCHA, C. R.; ARINI, T. S. Palliative Care for the Patient with Severe Neurological Damage Practice in Occupational Therapy. In: CONGRESS OF THE EUROPEAN ASSOCIATION FOR PALLIATIVE CARE, 11., 2009, Vienna. Proceedings... London: European Journal of Palliative Care, Hayward Medical Communications, 2009. p. 7-227.

OTHERO, M. B. et al. Assistência ao familiar e ao cuidador: projeto de atuação a partir de suas demandas e necessidades. In: GOMES, A. L. Z. (Org.). Prata da Casa 4: escritas do cotidiano de uma equipe que cuida. São Paulo: Oboré, 2011. p. 18-22.

PAIM, A. M. G. et al. Terapia Ocupacional: Contribuindo para a Função. In: DINI, L. I.; DALACORTE, A. (Orgs.). Cuidando do doente em casa: Um guia auxiliar para a reabilitação do paciente neurológico. Porto Alegre: Livre Comércio, 2009. p. 55-66.

PRADO, K. C. G.; FORMIGHIERI, P. F.; SANTANA, C. S. Cuidando de Idosos em Contexto Ambulatorial e Domiciliar: Percursos da Terapia Ocupacional em Gerontologia no HCFMRP-USP. In: UCHOAFIGUEIREDO, L. R.; NEGRINI, S. F. B. M. Terapia Ocupacional: Diferentes Práticas em Hospital Geral. Ribeirão Preto: Legis Summa, 2009. p. 289-303.

ROCHA, C. R. et al. Terapia Ocupacional em Assistência Oncológica Domiciliar - a Experiência da "São Paulo Internaçóes Domiciliares”. In: OTHERO, M. B. (Org.). Terapia Ocupacional: Práticas em Oncologia. São Paulo: Roca, 2010. p. 365-387.

ROSA, S. R.; ROSSIGALI, T. M.; SOARES, C. M. Terapia Ocupacional e o Contexto Familiar. Cadernos de Terapia Ocupacional da UFSCar, Sáo Carlos, v. 18, n. 1, p. 7-17, jan./abr. 2010.

SILVA, S. N. P.; KOVACS, A. C. T. B. Terapia Ocupacional na Atenção Domiciliar a Pacientes com Dor e em Cuidados Paliativos. In: DE CARLO, M. M. R. P.; QUEIROZ, M. E. G. (Orgs.). Dor e Cuidados Paliativos: Terapia Ocupacional e Interdisciplinaridade. São Paulo: Roca, 2007. p. 307-325.

STEULTJENS, E. M. J. et al. Occupational Therapy for Stroke Patients: A Systematic Review. Stroke, Dallas, v. 34 , n. 3, p. 676-687, 2003. PMid:12624291. http://dx.doi. org/10.1161/01.STR.0000057576.77308.30 